\title{
CONHECIMENTOS COMPARTILHADOS POR PROFESSORES E FUTUROS PROFESSORES NA ELABORAÇÃO E ANÁLISE COLABORATIVA DE SITUAÇÕES ADITIVAS
}

\author{
KNOWLEDGE SHARED BY TEACHERS AND FUTURE TEACHERS IN THE \\ PREPARATION AND COLLABORATIVE ANALYSIS OF ADDITIVE SITUATIONS
}

\author{
Flabruna Mendes de Almeida ${ }^{1}$; Ana Cláudia Gouveia de Sousa ${ }^{2}$, Christian Eduardo \\ Aragão dos Santos ${ }^{3}$
}

\begin{abstract}
RESUMO
A perspectiva colaborativa de formação e pesquisa é tomada no projeto FORPEM, que dá origem ao estudo apresentado neste texto, como metodologia para evidenciar conhecimentos e saberes dos professores, enquanto objeto de reflexão pelo grupo em colaboração. $\mathrm{O}$ referido projeto formativo por meio da pesquisa colaborativa, acontece em interação interinstitucional entre Educação Superior (UECE e IFCE), através de docentes e discentes de graduação e pós, e Educação Básica, através de seus professores. Participam do projeto, iniciado em 2019, 22 sujeitos, dentre as categorias citadas. A formação, iniciada em maio de 2020, acontece como um grupo de estudos voltado ao ensino de matemática, com mediações compartilhadas e busca da quebra das hierarquias no grupo. Após levantamento das necessidades formativas, o primeiro assunto eleito para os estudos coletivos foi as operações básicas, articulando saberes da prática docente, teoria matemática e Campo Conceitual Aditivo. A partir das negociações compartilhadas e estudos inicias, uma das atividades da pesquisa-formação foi a elaboração e discussão de situações aditivas, gerando compartilhamento de conhecimentos entre professores e futuros professores. Este texto, portanto, apresenta um recorte da pesquisa feita no âmbito desse projeto, e tem o objetivo de identificar conhecimentos docentes evidenciados na elaboração e análise colaborativa de situações aditivas. Para apresentar os resultados da investigação, este texto discute os conhecimentos para a docência, a colaboração e as estruturas aditivas; e analisa 3 das 11 situações elaboradas, bem como manifestações escritas dos participantes, registradas nas atividades reflexivas preenchidas por todos os integrantes. Como resultados, encontramos a importância do viés colaborativo, do grupo e do "outro" no reconhecimento dos aprendizados e
\end{abstract}

\footnotetext{
${ }^{1}$ Licencianda em Matemática pelo Instituto Federal de Educação Ciência e Tecnologia do Ceará (IFCE), Fortaleza, Ceará, Brasil. Endereço para correspondência: Rua João Triunfo, ${ }^{\circ}$ 618. Bairro Mucunã, Maracanaú - Ceará, Brasil, CEP: 61914-030. E-mail: flabrunaalmeida.eq@gmail.com.

(iD) ORCID iD https://orcid.org/0000-0003-0975-8259.

${ }^{2}$ Doutora em Educação pela Universidade Federal do Rio Grande do Norte (UFRN). Professora do Instituto Federal de Educação Ciência e Tecnologia do Ceará (IFCE), Fortaleza, Ceará, Brasil. Endereço para correspondência: Rua Soares Bulcão, 1521. Apto 1004, São Gerardo, Fortaleza, Ceará, Brasil, CEP: 60320-180. E-mail: anaclaudia@ @ifce.edu.br.

(iD) ORCID iD: https://orcid.org/0000-0001-5691-1610

${ }^{3}$ Licenciando em Matemática pelo Instituto Federal de Educação Ciência e Tecnologia do Ceará (IFCE), Fortaleza, Ceará, Brasil. Endereço para correspondência: Rua Alto das Pedrinhas, Parque Genibaú, Fortaleza, Ceará, Brasil, CEP 60534460. E-mail: christianeduardo637 @ gmail.com.

(D) ORCID iD: https://orcid.org/0000-0003-0770-6834.
} 
Flabruna Mendes de Almeida, Ana Cláudia Gouveia de Sousa e Christian Eduardo Aragão dos Santos Conhecimentos compartilhados por professores e futuros professores na elaboração e análise colaborativa de situações aditivas

conhecimentos dos participantes em relação às estruturas aditivas e à colaboração; confirmamos o papel da reflexão individual e coletiva na tomada de consciência dos participantes de um grupo quanto a suas aprendizagens; percebemos, ainda, as necessidades formativas do grupo no sentido de fazer avançar a colaboração como perspectiva mais horizontal de participação em um grupo formativo.

Palavras-chave: Formação de professores; Conhecimentos para a docência; Estruturas aditivas; Colaboração; Professores que ensinam Matemática.

\begin{abstract}
The collaborative perspective of training and research is taken in the project FORPEM, that gives rise to the study presented in this text, as a methodology to highlight teachers' knowledge and knowledge, as an object of reflection by the collaborating group. The referred training project through collaborative research, takes place in interinstitutional interaction between Higher Education (UECE e IFCE), through professors and students of undergraduate and postgraduate courses, and Basic Education, through their teachers. 22 subjects participate in the project, started in 2019, within the categories mentioned. The training, started in May 2020, takes place as a study group, with shared mediations and the search for breaking the hierarchies in the group. After surveying training needs, the first subject chosen for collective studies was basic operations, articulating knowledge of teaching practice, mathematical theory and the Addictive Conceptual Field. From the shared negotiations and initial studies, one of the research-training activities was the elaboration and discussion of addictive situations, generating knowledge sharing between teachers and future teachers. This text, therefore, presents an excerpt of the research carried out within the scope of this project, and aims to identify teaching knowledge evidenced in the elaboration and collaborative analysis of addictive situations. To present the results of the investigation, this text discusses knowledge for teaching, collaboration and additive structures; and analyzes 3 of the 11 situations elaborated, as well as written manifestations of the participants, recorded in the reflective activities completed by all members. As a result, we find the importance of the collaborative, group and "other" bias in recognizing the participants' learning and knowledge in relation to additive structures and collaboration; we confirm the role of individual and collective reflection in making group participants aware of their learning; we also perceive the group's training needs in order to advance collaboration as a more horizontal perspective of participation in a training group.
\end{abstract}

Keywords: Teacher training; Knowledge for teaching; Additive structures; Collaboration; Teachers teaching mathematics. 
Flabruna Mendes de Almeida, Ana Cláudia Gouveia de Sousa e Christian Eduardo Aragão dos Santos Conhecimentos compartilhados por professores e futuros professores na elaboração e análise colaborativa de situações aditivas

\section{Introdução}

Evidenciar os saberes e os conhecimentos para a docência tem sido um dos caminhos tomados na tentativa de compreender a formação de professores que ensinam matemática. Colocar os docentes na centralidade da discussão, reconhecendo-os como produtores de saberes e conhecimentos, tem integrado essa perspectiva de pesquisa acerca da formação, por entender a docência como profissão, ou seja, identificando que há, portanto, aprendizados profissionais específicos (SHULMAN, 1987; FIORENTINI, 2013; BALL, THAMES, PHELPS, 2008).

Nesse sentido, as discussões sobre a formação inicial e continuada de professores têm buscado compreender os saberes que os professores mobilizam em suas práticas pedagógicas, frutos dos conhecimentos advindos de diferentes fontes e constituídos também a partir das práticas diversas da profissão docente. Esse viés da evidenciação de conhecimentos e saberes tem sido também orientador de momentos formativos em instituições diversas.

Por saberes e conhecimentos, este artigo compreende a partir da discussão dos sentidos desses conceitos, travada em estudo de Mota, Prado e Pina (2008). Neste, os autores reconhecem as aproximações e distanciamentos desses conceitos, incluindo seu uso como sinônimos, mas sugerem uma maior aproximação de conhecimentos a ideias formais, conceitos e construções sistematizadas, enquanto que os saberes são constituídos por estes, mas acrescidos daqueles forjados nas práticas, nos aprendizados da experiência também. Atenção importante, no entanto, deve ser dada à articulação entre ambos, que acontece pela reflexão docente, como elemento de formação, sobretudo em contextos escolares e em colaboração entre diferentes sujeitos dos espaços educacionais e de pesquisa.

Dessa forma, a perspectiva colaborativa de formação e pesquisa (IBIAPINA, 2008; FIORENTINI, 2013), na confluência e interação entre os saberes dos atores da Instituição de Educação Superior (IES) e dos atores da Educação Básica (EB), é a base do projeto "Formação colaborativa de professores que ensinam matemática" - FORPEM. Vinculado à Universidade Estadual do Ceará (UECE) e ao Instituto Federal do Ceará (IFCE), acontece desde 2019 e envolve docentes da Educação Superior (ES) e da EB, e estudantes da graduação (Licenciatura em Matemática e Pedagogia) e do Programa de Pós-graduação em Educação da UECE. No FORPEM, a pesquisa sobre a formação 

Conhecimentos compartilhados por professores e futuros professores na elaboração e análise colaborativa de situações aditivas

docente acontece a partir de um processo formativo em colaboração. Inicialmente, foram levantadas necessidades formativas dos professores da EB, de forma a eleger os assuntos e metodologias de estudo, sendo as operações matemáticas básicas o primeiro tema eleito.

A formação tem acontecido, metodologicamente, como um grupo de estudos, em que buscamos quebrar a hierarquia, ouvir as diferentes vozes e aprender e ensinar juntos, vivenciando a alternância de papéis nos encontros formativos (IBIAPINA, 2008). Nesse formato, para estudar as operações básicas, iniciamos pelos saberes dos integrantes, principalmente docentes da EB, e depois buscamos aporte nas Estruturas Aditivas de Gèrard Vergnaud, para o diálogo teórico-prático de conhecimentos na constituição dos saberes do grupo. Dessa forma, portanto, como parte dos estudos, elaboramos situações aditivas em duplas, analisamos essas situações em subgrupos, depois no grupo maior. Esta ação, de elaboração e análise das situações, bem como o compartilhamento dos conhecimentos produzidos ao longo dela, constitui os dados analisados nesta investigação, que tem como objeto os conhecimentos evidenciados pelos docentes no processo de estudar, elaborar e analisar juntos situações aditivas.

Portanto, definimos como objetivo da pesquisa, ora apresentada: identificar conhecimentos docentes evidenciados na elaboração e análise colaborativa de situações aditivas. Este objetivo foi buscado pela discussão sobre formação colaborativa, conhecimentos para a docência e estruturas aditivas, e pela análise de situações elaboradas pelo grupo, bem como das escritas dos sujeitos em formação.

\section{Conhecimentos para a docência e colaboração na formação de professores que ensinam matemática}

Nas discussões acerca da formação de professores, a compreensão dos diferentes conhecimentos para a docência vem ganhando espaço. Shulman (2005) toma a discussão dos conhecimentos para a docência reconhecendo esta última como profissão, e o professor como o profissional que precisa de conhecimentos diversos, em articulação e vindos de diferentes fontes: a formação inicial na área de ensino; a realidade contextual e materiais educacionais institucionais (livro didático, currículo etc.); os resultados de pesquisas acerca do ensino, aprendizagem, ação docente etc.; e os saberes constituídos nas práticas (SHULMAN, 2005). 

Conhecimentos compartilhados por professores e futuros professores na elaboração e análise colaborativa de situações aditivas

Desta feita Shulman (2005) define, ainda, sete conhecimentos base para a docência: 1. Conhecimentos do Conteúdo: relativos à área de ensino do professor, o que deve ser conhecido em profundidade por ele, dando-lhe condições de relacionar com contextos e demais áreas do conhecimento; 2. Conhecimento Didático: as formas de ensinar e os princípios que regem essas formas; 3. Conhecimento do Currículo: entendimento do professor relativo a documentos curriculares oficiais, materiais didáticos e outros; 4. Conhecimento Didático do Conteúdo: articulação entre o conteúdo de ensino e a pedagogia - princípios, estratégias metodológicas, recursos etc., mas voltandoos aos assuntos a serem ensinados e suas especificidades; 5. Conhecimento dos Estudantes e suas Características: compreensão sobre a aprendizagem e desenvolvimento dos alunos, considerando seus contextos culturais, históricos e sociais, além dos seus conhecimentos prévios; 6. Conhecimento dos Contextos Educativos: referente à comunidade, à qual pertence o aluno e a escola, além das características culturais e ambientais; 7. Conhecimentos dos Objetivos, Metas e Valores Educacionais e seus Fundamentos Filosóficos e Históricos: o nome já aponta para o intuito de pôr em relevo objetivos, valores e metas educacionais essenciais à prática docente, também pela compreensão da fundamentação histórica e filosófica para tal.

Shulman atenta que esses conhecimentos não são fixos ou definitivos. São uma base compreendida e transformada pelo professor no ato de ensinar, em que compreensão refere-se à forma de entender do professor - dos conteúdos, sua estrutura, relações, objetivos, dentre outros. E a transformação é o ato que acontecerá para levar essa compreensão ao ensino, o que envolve preparação, representação das ideias, seleções didáticas e adaptações relativas às características dos alunos e dos contextos sociais e culturais. E, para o professor tomar consciência sobre seu pensar e fazer, a reflexão tem papel central. A reflexão que busca articular teoria e prática, reconhecendo saberes constituídos nessa prática.

Uma forma de fazer acontecer esse reconhecimento consciente, é ter a colaboração como princípio de pesquisa e formação (IBIAPINA, 2008; FIORENTINI, 2013; ANJOS, NACARATO e FREITAS, 2018). O professor, na pesquisa colaborativa, não é considerado objeto de estudo, mas promotor ativo da pesquisa, tornando sua prática docente objeto de investigação e intervenção, mas com sua participação. Na pesquisa colaborativa, todos os participantes são ativos e contribuintes, estabelecendo ações que 

Conhecimentos compartilhados por professores e futuros professores na elaboração e análise colaborativa de situações aditivas

se desenvolvem no âmbito da tomada de consciência sobre seus saberes e fazeres docentes, para o trabalhar juntos, quebrando as hierarquias tanto quanto possível, alcançando ajuda mútua e o cumprimento dos objetivos de definição coletiva. Dessa forma, “as aprendizagens são recíprocas e o outro - a professora, as formadoras, as pósgraduandas - ocupa papel central, com o seu excedente de visão" (ANJOS, NACARATO e FREITAS, 2018, p. 207).

\section{Campo conceitual aditivo: diferentes estruturas das situações aditivas}

A Teoria dos Campos Conceituais - TCC - desenvolvida pelo pesquisador francês Gérard Vergnaud, sob a influência Piagetiana, busca fornecer um referencial para os educadores compreenderem como os alunos constroem os conhecimentos matemáticos. Esta teoria visa explicar o processo que leva à formação dos conceitos que envolvem estruturas aditivas e multiplicativas, bem como ideias algébricas e identificação das relações numéricas-espaciais (VERGNAUD, 1993).

Vergnaud (1993) afirma que os conceitos matemáticos são constituídos, ao longo do tempo, mediante a vivência com uma variedade de situações, tanto no ambiente escolar quanto fora dele, dependendo de maturidade e aprendizagem (MOREIRA, 2002). Para o pesquisador, frequentemente, cada situação não pode ser analisada com base em apenas um conceito, e um conceito não pode ter significado a partir de apenas uma situação isolada. Dessa forma, a aquisição de conhecimento ocorre através de um conjunto de situações e conceitos, o que é concebido, pela teoria, como campos conceituais. Vergnaud (1982) define campo conceitual como: "um conjunto informal e heterogêneo de problemas, situações, conceitos, relações, estruturas, conteúdos e operações de pensamento, conectados uns aos outros e, provavelmente, entrelaçados durante o processo de aquisição" (VERGNAUD, 1982, p. 40).

Ao referir-se a conceito, Vergnaud (1993) nos apresenta a tríade de conjuntos (S, I, R) que sustentam sua formação. Esta tríade é composta por: $\mathbf{S}$ : conjunto de Situações que dão sentido ao conceito (a referência); I: conjunto de Invariantes, os quais os sujeitos podem identificar e utilizar para analisar e apreender essas situações (o significado); R: conjunto de formas de linguagem que podem ser utilizadas para Representar simbolicamente esses invariantes e, desse modo, representar as situações e os procedimentos de tratamento (o significante). 

Conhecimentos compartilhados por professores e futuros professores na elaboração e análise colaborativa de situações aditivas

Essas situações $(\mathrm{S})$ referem-se às realidades trabalhadas pelos estudantes em sala de aula, relativas à contagem, jogos, relações entre quantidades. O trabalho didático com elas acontece a partir da identificação dos invariantes (I) presentes nelas, que implicam nas estratégias dos estudantes para resolvê-las. Através dessas resoluções, pode-se analisar as simbologias, as representações (R) que os estudantes usam em seus registros.

Cada campo conceitual tem um conjunto de situações que dão sentido ao conceito. Nesta pesquisa, concentramo-nos no campo conceitual aditivo, mais especificamente no entendimento das estruturas aditivas nesse campo. Para a construção do conhecimento sobre este campo, Vergnaud (1993) explica que é necessário o trabalho com um conjunto de situações de adição, subtração ou combinação das duas. Portanto, a continuação deste estudo requer a diferenciação dos tipos de situações aditivas, e a apresentação de suas classificações. Magina et. al. (2001) classificam as situações aditivas em três grupos básicos - composição, transformação e comparação.

A Composição contém as situações nas quais se têm um todo e suas partes, e em que a reunião das partes forma o todo. Situações em que subtraindo uma parte do todo obtém-se a outra parte. Exemplo 1: João tem 6 carrinhos e 4 bonecos. Quantos brinquedos João tem?

A Transformação compreende as situações em que há uma ideia de temporalidade, ou seja, têm sempre um estado inicial, uma transformação e um estado final. Exemplo 2: Laura tinha 9 bonecas e ganhou 3 bonecas de sua prima. Quantas bonecas Laura tem agora?

Já a Comparação é relativa às situações que envolvem uma relação de comparação entre duas quantidades, em que uma é o referente e a outra é o referido. Exemplo 3: Carlos tem 7 bolas de gude. José tem 4 bolas de gude a mais que Carlos. Quantas bolas de gude José tem? Nessa situação é dada a quantidade de bolas de gude que Carlos tem, e é pedida a quantidade que José tem em relação à quantidade de Carlos (quatro bolas de gude a mais que Carlos). Logo, a quantidade de bolas de gude que Carlos tem serve como referência, ou seja, é o referente da situação, para que se obtenha a quantidade de bolas que José tem, o referido da situação.

Dentre esses três grupos, têm-se as situações denominadas por Magina et. al. (2001) de protótipos das estruturas aditivas, pois são os primeiros problemas de adição e 

Conhecimentos compartilhados por professores e futuros professores na elaboração e análise colaborativa de situações aditivas

de subtração que os estudantes conseguem dominar no seu cotidiano escolar, ou antes dele, e que servirão como modelo para o resto da vida desses estudantes.

O protótipo 1 de adição, como as autoras chamam, pertence ao grupo de problemas de composição. O Exemplo 1 é considerado como protótipo, pois a ideia envolvida nessa situação é apenas a de juntar as partes, em que os valores já são apresentados no problema de forma explícita. Essa situação é "justamente a primeira situação de adição que a criança compreende" (MAGINA et. al., 2001 p. 30).

O protótipo 2 de adição e subtração pertence ao grupo de problemas de transformação, pois são dados o estado inicial e uma transformação, e é pedido o estado final. É uma situação em que o estudante consegue associar o "ganhar' com a operação de adição e o "perder" com a operação de subtração. Um exemplo para esse tipo de protótipo é o Exemplo 2.

Segundo Magina et. al. (2001) as situações problemas compreendidas nesses dois protótipos podem ser consideradas como modelos básicos, em relação à complexidade que as situações podem envolver nesse campo conceitual. As classificações apresentadas a seguir são consideradas pelas autoras, como extensões das estruturas aditivas, extensões desses protótipos. São situações que requerem do estudante teoremas em ação mais aprimorados, por serem mais complexas.

Essas situações podem ser divididas em três extensões:

$1^{\text {a }}$ Extensão: envolve dois tipos de problemas. O primeiro pertence ao grupo de problemas que envolvem a transformação, em que aparecem o estado inicial e o estado final, mas não a transformação. Nesse problema a transformação é desconhecida. Exemplo 4: Júlia foi ao mercado, fazer compras, com $\mathrm{R} \$ 50,00$. Quando voltou do mercado viu que ficou com $\mathrm{R} \$ 5,00$. Quanto Júlia gastou? O segundo tipo pertence ao grupo de problemas que envolvem composição, com uma das partes desconhecida. Exemplo 5: Joana tem três filhas, a soma das idades de suas filhas é igual a 19. A primeira filha tem 12 anos, a segunda tem 2 anos. Quantos anos tem a terceira filha?

$2^{\text {a }}$ Extensão: envolve o problema de comparação, em que o referente e a relação são dados, e o referido é desconhecido. Um exemplo para esse tipo de extensão é o Exemplo 3, já mencionado neste texto.

$3^{\mathrm{a}}$ Extensão: compreende o problema de comparação, em que o referente e o referido são dados, porém não fica explícito para o estudante quem é referente e quem é 

Conhecimentos compartilhados por professores e futuros professores na elaboração e análise colaborativa de situações aditivas

referido, e a relação entre eles é desconhecida. Exemplo 6: Carlos tem 4 bolas e João tem 10 bolas. Quem tem mais bolas? Quantas a mais?

$4^{\mathrm{a}}$ Extensão: nesta extensão estão compreendidos os problemas que envolvem tanto transformação quanto comparação. Estes problemas estão nessa categoria, pois "requerem do aluno um raciocínio aditivo mais sofisticado dentre o grupo de problemas básicos." (MAGINA et. al., 2001). O primeiro problema envolve transformação, cujo estado inicial é desconhecido. Exemplo 7: João tinha algumas figurinhas e deu 13 figurinhas para o seu colega, ficando com 17 figurinhas. Quantas figurinhas João tinha antes? O segundo problema envolve comparação, cujo referente é desconhecido. Exemplo 8: Carla tem algumas bonecas e Joana tem 7 bonecas a mais que Carla. Sabendo que Joana tem 20 bonecas, quantas bonecas tem Carla?

Segundo estudos das autoras mencionadas, esses problemas são considerados os mais difíceis para os estudantes, pois é necessário que eles saibam fazer operações inversas ao que eles estão acostumados a fazer para chegar no resultado correto.

Magina et. al. (2001) apresentam, ainda, outras situações, que as autoras chamam de "problemas mistos". Essa denominação é porque, diferentemente dos problemas apresentados até aqui, estes envolvem mais de um raciocínio aditivo simultaneamente. Para as autoras, o objetivo de apresentar esses "problemas mistos" é mostrar que há várias possibilidades de combinar dois ou mais raciocínios aditivos. Como são apresentados.

Composição de transformações: Nesses tipos de situações, o problema apresentado é, como o próprio nome nos informa, uma composição de várias transformações. Exemplo 9: Clara tinha alguns sapatos, ganhou 5 sapatos num sorteio, ficando com 15. Posteriormente, deu à sua irmã 4 sapatos. Com quantos sapatos Clara ficou no final?

Transformação de Composição: São situações que envolvem tanto transformação quanto composição. Exemplo 10: No meu estojo havia 10 canetas azuis e 5 canetas vermelhas. Ontem ganhei 3 canetas pretas e 2 canetas verdes. Quantas canetas ao todo ficaram no estojo?

Comparação com composição de transformações: Considerado o mais complexo e mais extenso dos problemas mistos apresentados até agora, exige do aluno uma atenção maior na leitura e interpretação do problema. Exemplo 11: Joca, João e Carla foram ao shopping passear. Joca levou $\mathrm{R} \$ 50,00$; João levou $\mathrm{R} \$ 20,00$ a menos que Joca e Carla 
Flabruna Mendes de Almeida, Ana Cláudia Gouveia de Sousa e Christian Eduardo Aragão dos Santos Conhecimentos compartilhados por professores e futuros professores na elaboração e análise colaborativa de situações aditivas

levou R \$40,00 a mais que João. Joca acabou gastando o mesmo que João havia levado para o passeio. Tanto João quanto Ana gastaram a metade do dinheiro que haviam levado. Agora pergunta-se: Quanto dinheiro João e Ana levaram, respectivamente? Quanto cada um gastou? Com quanto cada um ficou no final do passeio?

Para a TCC é patente a importância da variabilidade de situações que devem ser propiciadas aos estudantes ao longo do processo de aprendizagem. Ademais é importante ressaltar que a aprendizagem do campo conceitual aditivo pelo estudante requer um longo período de tempo, pois demanda experiência com uma diversidade de situações, com uma multiplicidade de conceitos relacionados à adição e subtração. Mais uma razão para estudarmos essa temática com professores das 09 (nove) séries do EF.

\section{Percurso metodológico de um projeto de formação e pesquisa}

Este é o recorte de um estudo de abordagem qualitativa, realizado no âmbito de uma pesquisa-formação de viés colaborativo. $O$ projeto abrange parceria interinstitucional entre três campi de duas Instituições de Educação Superior (ES) e professores da Educação Básica (EB). Os sujeitos são professores do ES, alunos de graduação e pós-graduação e docentes da EB, que ensinam Matemática no Ensino Fundamental (EF), tanto anos iniciais quanto finais.

O projeto, iniciado no segundo semestre de 2019, teve os encontros formativos iniciados em maio de 2020. Após as mudanças decorrentes da Pandemia da Covid-19, os encontros passaram a acontecer pelo Google Meet, mensalmente, de acordo com a disponibilidade dos integrantes. Tínhamos ainda, na realização das atividades, o apoio do Google Classroom. Ainda como parte da estrutura metodológica da formação, após cada encontro, todos os participantes são convidados a responder uma atividade reflexiva, enviada por formulário do Google, com o intuito de sistematização das aprendizagens, dúvidas, percepções acerca de si, do encontro, do grupo e do tema abordado, bem como sugestões para o encontro seguinte.

Os encontros formativos, numa concepção de grupo de estudos, iniciaram-se pelo levantamento das necessidades formativas do grupo, a partir do qual foram eleitos vários assuntos em sequência, sendo o primeiro as operações básicas. Para o diálogo das práticas docentes compartilhadas pelos professores, com os aspectos teóricos, além da própria teoria matemática, buscamos aporte nas Estruturas Aditivas de Gèrard Vergnaud, assunto 

Conhecimentos compartilhados por professores e futuros professores na elaboração e análise colaborativa de situações aditivas

que o grupo passou a estudar, ler e discutir. Uma das atividades desses estudos, na tentativa de articulação entre teoria e prática, foi a elaboração de situações aditivas em duplas. O grupo de 20 sujeitos elaborou 11 situações, que foram discutidas em subgrupos, com posterior socialização dessas discussões no grupo maior.

A empiria analisada nesse recorte do projeto são registros contidos nas atividades reflexivas mencionadas, e que se referiam a aprendizados reconhecidos nas ações de elaborar e compartilhar as percepções dos docentes, bem como situações aditivas elaboradas no citado contexto colaborativo de formação, pesquisa e reflexões, e as discussões sobre elas.

Analisamos, portanto, na seção seguinte, três situações aditivas elaboradas por participantes do grupo, uma de cada tipo - composição de quantidade, transformação de quantidade e comparação de quantidade. Em seguida identificamos conhecimentos para a docência evidenciados especificamente por professores e futuros professores, relativos às estruturas aditivas, ao ensino de Matemática e à colaboração como perspectiva formativa.

\section{Conhecimentos revelados na elaboração e análise de situações aditivas}

Inicialmente, apresentaremos e analisaremos três situações, selecionadas com base nos três tipos já apresentados anteriormente.

\section{Análise das situações aditivas elaboradas}

Situação 1: Ana foi à feira com sua mãe para comprar frutas. O irmão de Ana gosta de laranja, então sua mãe comprou para ele 15 laranjas, e para Ana 12 maçãs. Quantas frutas foram compradas ao todo?

Nesta situação, temos um caso de composição, em que a quantidade de laranjas é uma parte, a quantidade de maçãs é a outra parte e a soma dessas duas partes forma o todo, que é a quantidade de frutas que foram compradas por Ana, no caso, 27 frutas. É uma situação prototípica em que, segundo Magina et. al. (2001), o estudante consegue resolvê-la de forma intuitiva, usando um raciocínio que vem sendo formado desde sua infância.

Essa situação foi elaborada por uma dupla formada por uma professora EB e uma aluna de Pedagogia. Na discussão, o grupo teve facilidade em identificar o tipo de situação, ratificando seu caráter intuitivo previsto no estudo de Magina et. al. (2001), 
Flabruna Mendes de Almeida, Ana Cláudia Gouveia de Sousa e Christian Eduardo Aragão dos Santos Conhecimentos compartilhados por professores e futuros professores na elaboração e análise colaborativa de situações aditivas

inclusive para a elaboração pelas participantes e possível resolução pelos estudantes, na concepção do grupo.

Situação 2: (adaptada) ${ }^{4}$ Carlos tinha 14 bolas de gude quando saiu para jogar. Ele jogou a primeira partida, mas não disse o que tinha acontecido. Jogou a segunda e disse que tinha ganho 3 bolas de gude. Ele voltou para casa com 17 bolas de gude. O que aconteceu na primeira partida?

Este é um caso de composição de transformações de $1^{\text {a }}$ extensão, ou seja, uma das transformações é desconhecida. Temos o estado inicial, que é 14 bolas de gude, e posteriormente essa quantidade vai sofrendo duas transformações. A primeira transformação (t1) acontece quando Carlos jogou a primeira partida, mas essa ainda é desconhecida pois Carlos não informa o que aconteceu. Já a segunda transformação (t2) acontece quando ele joga a segunda partida, em que ele informa que ganhou 3 bolas de gude. $\mathrm{O}$ estado final é apresentado, ele voltou para casa com 17 bolas de gude. Para saber o que aconteceu na primeira partida, o estudante deve analisar: se o estado inicial era 14 bolas de gude e o estado final 17 bolas, então no total houve um ganho de 3 bolas de gude. Essa quantidade foi a mesma quantidade da $\mathrm{t} 2$, logo na $\mathrm{t} 1$ não houve ganho nem perda, ou seja, $\mathrm{t} 1=0$.

Essa situação foi elaborada por uma professora ES e uma aluna de graduação (Pedagogia), e gerou muita discussão no grupo. Os aspectos que geraram as discussões foram: a componente contextual sobre o jogo de bola de gude, em que não daria para terminar uma primeira partida sem ganhar ou perder, alguns diziam que sim, outros que não, a depender das regras. E essa informação de contexto tem caráter decisivo na compreensão do problema, visto que o aluno faz a relação com seu conhecimento de mundo. Estritamente acerca da estrutura do problema, o grupo debateu, evidenciou aspectos do raciocínio algébrico presentes nele, e que essa é uma situação que pode ser trabalhada nos anos finais do EF também.

Situação 3: A taxa de transmissão da Covid-19 em Fortaleza vem recuando de forma sistemática há 46 dias, segundo dados atualizados em 05/10/2020. Esses dados também apontam que o $\mathrm{n}^{\mathrm{o}}$ de óbitos por essa doença no Nordeste é de 39.579 (FONTE: Diário do Nordeste, 05/10/2020), ou seja, 30.525 a mais que a quantidade de óbitos no

\footnotetext{
4 A adaptação foi na substituição da palavra "bila" (utilizada no Ceará) por bola de gude, mais conhecida nacionalmente.
} 

Conhecimentos compartilhados por professores e futuros professores na elaboração e análise colaborativa de situações aditivas

Ceará. Assim, quantos óbitos estão registrados no Ceará, por covid-19, até 05/10/2020, segundo esses dados?

Esse tipo de situação é considerada de comparação - $4^{\mathrm{a}}$ extensão -, pois apresenta um grau maior de complexidade. Observe que quantidade de óbitos no Ceará, a ser encontrada, é a referência nessa situação, visto que o $n^{\circ}$ de óbitos no Nordeste está representado em termos de quantos a mais o Nordeste tem em relação à quantidade que o Ceará tem. A complexidade desse tipo de situação se deve ao fato de não ter explícita a quantidade que é o ponto de partida, a referência, para o estudante conseguir construir seus cálculos. A resolução precisa tomar em conta apenas referido (39.579) e relação (30.525), o que complexifica a estrutura e consequentemente as estratégias de resolução. Além disso, tem o fato de colocar em jogo números grandes.

Essa situação gerou grande debate, tanto nos subgrupos, quanto no grupo, pois havia sérias dúvidas quanto à referente, referido e relação, e os papéis que esses aspectos da extensão da situação teriam na compreensão e resolução da situação pelos estudantes. Além disso, foi vista como situação a ser trabalhada também nos anos finais, além dos iniciais - $5^{\circ}$ ano -, pela complexidade e grandeza numérica.

Nas discussões das situações, tanto nos subgrupos quanto no grupo maior, os participantes articulavam conhecimentos do conteúdo, pedagógico do conteúdo, dos estudantes e do currículo na demonstração de suas elaborações conceituais, como detalhamos a seguir.

\section{Conhecimentos compartilhados na elaboração e discussão das situações:}

Nesta seção apresentaremos e analisaremos conhecimentos compartilhados por sujeitos do grupo sobre as atividades de elaborar e analisar as situações aditivas, colocando ênfase nos conhecimentos para a docência e nos aspectos colaborativos que se sobressaem. Os sujeitos são identificados como FP (futuros professores) e P (professores da Educação Básica).

Sobre a situação 3, como mencionado, foi um dos tipos de problemas que gerou dúvidas nos participantes, durante a discussão nos encontros, pois muitos de nós não conseguimos, inicialmente, identificar o referente e o referido na situação. E foram exatamente as discussões em grupo, na visão dos integrantes, que possibilitaram essas dúvidas serem sanadas, como podemos perceber na fala de um dos participantes: 


\begin{abstract}
A discussão em pequenos grupos possibilitou o confronto de opiniões e argumentos sobre as situações, eu por exemplo tinha dificuldade em identificar o referente e o referido em uma situação de comparação, levei essa dificuldade ao pequeno grupo e vi que essa dificuldade não era só minha, então chegamos a decisão de levar essa discussão ao grupo todo, pois não conseguimos entrar em consenso no pequeno grupo. Com a discussão no grupo eu consegui compreender o que é o referente e o que é o referido, a partir dos questionamentos de uma das profas pesquisadoras (FP 1).
\end{abstract}

FP1 coloca em questão aspectos do conhecimento do conteúdo estudado pelo grupo. E explicita a necessidade de apoio e o papel do "outro" no subgrupo e no grupo maior para discutir e tentar compreender o que ainda não foi compreendido por ele e seus pares, como afirmam Anjos, Nacarato e Freitas, 2018. A iniciativa de levar para a discussão no subgrupo e no grupo denota um reconhecimento desses espaços voltados ao aprendizado, e como lugar seguro para a exposição do não saber (ainda), perspectiva buscada pelo viés colaborativo.

O conhecimento pedagógico do conteúdo aparece como importante aprendizado reconhecido pela professora $\mathrm{P} 1$, quando esta compartilha que:

Ao elaborar a atividade com a minha dupla, descobri uma outra estratégia para representar uma situação aditiva, que foi a reta numérica. Não tinha conhecimento dessa estratégia, como possibilidade para resolução de um problema aditivo. $(\mathrm{P} 1)$

Essa "descoberta" de mais uma possibilidade de representação da situação, como estratégia de resolução, aponta para um conhecimento pedagógico do conteúdo que a professora reconhece a partir da sua interação colaborativa com outra professora EB. Ela evidencia em seu registro escrito, como a colaboração em dupla, com a colega professora com quem elaborou sua situação, trouxe aprendizado relevante para sua prática docente. Podemos apontar, ainda, o conhecimento do conteúdo, já que as diferentes representações utilizadas como estratégia de resolução da situação, são componente fundamental para a conceituação, segundo Vergnaud (1993).

Ainda sobre evidências de colaboração, mas no caso, a partir da discussão no grupo maior, o professor $\mathrm{P} 2$ registra que:

As discussões realizadas no grupo permitem encontrar as estratégias dos alunos para resolver os problemas, além de estimular uma nova abordagem de conceitos trabalhados em sala de aula. (P2). 

Conhecimentos compartilhados por professores e futuros professores na elaboração e análise colaborativa de situações aditivas

Essa sistematização escrita do docente nos permite perceber articulações entre conhecimento dos alunos e suas características, conhecimento pedagógico do conteúdo e conhecimento do conteúdo. Nesse sentido vemos a compreensão e transformação de que trata Shulman (2005), registradas na reflexão escrita do professor.

\section{Considerações Finais}

A apresentação deste estudo nos proporcionou sistematizar percepções sobre o processo colaborativo vivenciado na formação por meio da pesquisa. Proporcionou também um olhar mais apurado sobre a Teoria dos Campos Conceituais, especificamente o Campo Conceitual Aditivo, e seu uso na formação docente, como aporte para a elaboração e análise colaborativa de situações aditivas. Destacamos, portanto, os conhecimentos evidenciados pelos professores e futuros professores participantes do projeto, na elaboração e análise grupal das referidas situações: conhecimentos do conteúdo, pedagógicos, pedagógicos do conteúdo, do currículo e dos estudantes; reconhecimento da relevância do grupo colaborativo como espaço seguro e confiável para o erro, a dúvida e o aprendizado. Reconhecemos, ainda, a necessidade de mais estudos sobre a perspectiva colaborativa, para a quebra das hierarquias, visto que a autoridade das professoras da ES ainda é vista como legitimadora de saberes no grupo.

\section{Referências}

ANJOS, D. D; NACARATO, A. M; FREITAS, A. P. de. Práticas colaborativas: o papel do outro para as aprendizagens docentes. Educação Unisinos. 22(2): 204-213, abriljunho, 2018. Unisinos - doi: 10.4013/edu.2018.222.10

BALL, Deborah Loewenberg; THAMES, Mark Hoover; PHELPS, Geoffrey Charles. Content Knowledge for Teaching: what makes it special? Journal of Teacher Education, v. 59, n. 5, p. 389- 407, 2008.

FIORENTINI, Dario. Pesquisar práticas colaborativas ou pesquisar colaborativamente? In: BORBA, Marcelo de Carvalho; ARAÚJO, Jussara de Loiola. (Orgs.). Pesquisa qualitativa em educação Matemática. Belo horizonte: Autêntica Editora, 2013.

IBIAPINA, I. M. L. M. Pesquisa Colaborativa: investigação, formação e produção de conhecimentos. Brasília: Editora Liber Livro, 2008. 
Flabruna Mendes de Almeida, Ana Cláudia Gouveia de Sousa e Christian Eduardo Aragão dos Santos Conhecimentos compartilhados por professores e futuros professores na elaboração e análise colaborativa de situações aditivas

MAGINA, S.; CAMPOS,T; NUNES,T., GITIRANA,V. Repensando Adição e

Subtração: Contribuições da Teoria dos Campos Conceituais, Ed. PROEM Ltda, São

Paulo, 2001

MOREIRA, M. A. A teoria dos campos conceituais de Vergnaud, o ensino de Ciências e a pesquisa nesta área. Investigações em Ensino de Ciências, v.7, n.1, 2002.

Disponível em: 〈http://www.if.ufrgs.br/public/ensino/revista.htm>.

MOTA, D. A. D.; PRADO, G. do V. T.; PINA, T. A. Buscando possíveis sentidos de saber e conhecimento na docência. Cadernos de Educação | FaE/PPGE/UFPel | Pelotas [30]: 109 - 134, janeiro/junho 2008.

VERGNAUD, G. A Classification of Cognitive Tasks and Operations of Thought Involved in Addition and Subtraction Problems. In. T. Carpenter; T. Romberg; J. Moser (Eds.). Addition and Subtraction: a cognitive Perspective. New Jerssey: Lawrense Erlbaun, 1982. p. 39-59.

VERGNAUD, G. Teoria dos campos conceituais. In: NASSER, L. (Ed.). SEMINÁRIO INTERNACIONAL DE EDUCAÇÃO MATEMÁTICA, 1, 1993, Rio de Janeiro. Anais do Seminário Internacional de Educação Matemática. p. 1-26.

SHULMAN, Lee S. Knowledge and teaching: foundations of the new reform. Harvard Educational Review, Cambridge, v. 57, p. 1-22, 1987.

SHULMAN, Lee S. Conocimiento y enseñanza: fundamentos de la nueva reforma. Profesorado. Revista de Currículum y Formación de Profesorado. v.9, n.2, Granada, España, 2005, pp.1-30.

Recebido em: 07 / 03 / 2021

Aprovado em: 25 / 04 / 2021 